\title{
Ignacio Ellacuría y el \\ 只 horizonte del bien común de la humanidad
}

\section{Juan Antonio Senent-De Frutos \\ Universidad Loyola}

Resumen: Realizamos en este trabajo una lectura genealógica, y a su vez, una actualización y proyección del criterio ético-político del bien común en el contexto de la sociedad global actual. Para ello, realizamos un diálogo crítico sobre el significado de este criterio en autores clásicos de la tradición occidental, y sobre el modo en que han sido empleados y resignificados en las sucesivas épocas hasta nuestros días. En ese diálogo y para esa reconstrucción, prestamos especial atención al sentido civilizatorio y normativo que juega el bien común en los pensadores jesuitas en el mundo globalizado que surge desde el siglo XVI, como Francisco Suárez (1548-1617), y particularmente desde la conciencia de crisis e insostenibilidad de los dinamismos que rigen en ese mundo global, y que se analiza en la obra de Ignacio Ellacuria (1930-1989). Así, mostramos la pertinencia crítica y ética del criterio del bien común de la humanidad desde nuestros desafios históricos, como elemento normativo para evaluar, orientar y relanzar éticamente las interacciones y las plurales prácticas e instituciones sociales que operan en la sociedad mundial.

Palabras claves: Bien común, bien común de la humanidad, Ignacio Ellacuria, Francisco Suárez, sociedad mundial.

Abstract: / carry out in this work a genealogical reading and, at the same time, an update and projection of the ethical-political criterion of the common good in the context of today's global society. To do this, I maintain a critical dialogue about the meaning of this criterion in the classical authors of the western tradition, and about the way in which they have been used and resignified in the successive times until today. In this dialogue and for this reconstruction, I pay special attention to the civilizing and normative sense that the common good plays in Jesuit thinkers in the globalized world that emerged from the 16th century, such as Francisco Suárez (1548-1617), and particularly from the conscience crisis and unsustainability of the dynamisms that rule in this global world, and which is analyzed in the work of Ignacio Ellacuria (1930-1989). Thus, I show the critical and ethical relevance of the criterion of the common good of humanity from our 
historical challenges, as a normative element to ethically evaluate, guide and rebuild the interactions and plural practices and social institutions that operate in world society.

Keywords: Common good, common good of humanity, Ignacio Ellacuria, Francisco Suárez, world society.

\section{Introducción y perspectiva del problema}

Quiero hacer una contribución filosófica en orden a la búsqueda de una justicia cosmopolita ${ }^{1}$, históricamente situada como estrategia de respuesta a las diferentes crisis socioambientales que se experimentan en el ámbito de la sociedad global. Por perspectiva filosófica no quiero significar, como a veces popular e incluso científicamente se supone, que se trate de un juego de conceptos desconectados de los procesos empírico-reales y carentes, a su vez, sin incidencia práctica. Inspirado por la perspectiva ética de Ellacuría, se trata más bien de articular una razón teórica crítica con una razón práctica éticamente sustentada que nos permita tanto un entendimiento crítico de los procesos en los que la humanidad actual define la producción de mundo, como un relanzamiento ético de los procesos en una dirección más humanizadora y sostenible.

Orientarnos hoy por una dirección más humanizadora de la sociedad, implica atender a la dimensión mundial de una única sociedad global que de forma desigual y dialéctica incluye y condiciona a las diversas sociedades o pueblos de la tierra. La perspectiva ética ellacuriana, partía fácticamente de esta situación. Desde ella se puede articular un ideal ético a la altura de la realidad procesual de la humanidad que parta de un punto de vista universal, real y no ideologizado, que incluya y considere por tanto a la humanidad actual en su pluralidad, antagonismos, y en sus posibilidades de humanización.

En la realización abierta y responsable de los dinamismos sociales es donde se va a decidir la configuración que finalmente asuma la realidad humana. $Y$ desde esta apertura y ambigüedad de los dinamismos humanos, se alzará la posibilidad ética de que las personas "se esfuerce[n] creativamente por dar un sentido a la historia y por intentar la construcción de una realidad personal, social e histórica que permita la realización de ese sentido" (Ellacuría, 2001a, p. 243)

Si un ideal ético está ajustado a las necesidades de superación de las 
estructuras y dinamismos deshumanizadores ayuda a orientar la liberación de la historia. La humanización de la historia desde cada sujeto, grupo humano, y en última instancia del conjunto de la humanidad, es una lucha por introducir una "novedad" en la historia para dar de sí una vida más plena y un mundo no roto ni dialécticamente enfrentado como dato definitivo, en búsqueda de una vida sostenible como superación de modos de vida humanos no universalizables históricamente.

El sentido de la historia es hacerla, y no es una simple tautología. O la vida y la historia merece ser vivida y realizada o nos caemos por el precipicio del nihilismo. Y en esta línea, cuando Ellacuría plantea el proceso histórico no como un mero proceso de hominización, o de mero despliegue biológico de la especie humana, sino también y principalmente como un proceso de humanización, está planteando el mismo problema; o también cuando plantea el problema radical de los derechos humanos como una lucha por la vida y en contra de aquello que produce muerte y negación. $\mathrm{O}$ bien la vida humana y la realización de la humanidad se afirma y libera sus mejores virtualidades o estamos abocados al fracaso. La vida debe ser vida digna y no vida negada, y la historia hecha por las personas, en última instancia por el conjunto de la humanidad, y no padecida como un proceso que nos arrastra, amenaza y cosifica. Es decir, o vivimos una vida con sentido, y una historia con sentido, o no tiene sentido vivirla ni hacerla. Pero ello, no nos lanza a un abandono rápido de la vida o de la historia, ni a un suicidio individual ni colectivo. Nos invita, si queremos hacernos cargo de la densidad de lo real y de sus posibilidades, a no dejarnos engañar por las apariencias de lo que hay como lo definitivo; de la ruptura y la enemistad como el último dato de lo humano; a una rebeldía contra el mal sufrido y la alienación; a una lucha por la vida y la solidaridad en contra de la muerte infringida y la negatividad sentida ${ }^{2}$; no a la espera, sino a la esperanza activa de los que construyen y hacen irrumpir otro futuro en medio del presente. Siempre en la facticidad hay un "más", que sólo se ve o desarrolla por la esperanza que anima la profecía y la utopía: "profetismo utópico que desde la negación anuncia un futuro mejor y concreta los modos de su realización" (Senent de Frutos 2012: 370).

Al hilo de este análisis, debemos primero reconocer, y en un segundo paso precisar y perfilar las dimensiones del ideal utópico y ético que puede mover hoy las prácticas sociales críticas. En el conjunto de la negatividad sentida por muchos grupos sociales de la humanidad, las actuales praxis críticas e instituyentes animadoras de otra construcción histórica convergen en una cierta orientación utópica. Se orientan por un criterio utópico 
de justicia que podemos formular como bien común humano de la humanidad, donde también se dé y articule un cierto bien común de la naturaleza en el que se desenvuelven las prácticas plurales de la propia humanidad.

Antes de entrar en una propuesta analítica de las dimensiones del bien común de la humanidad, puede ayudarnos un cierto apunte genealógico de tradiciones histórico-culturales que han ido ensanchando el horizonte de entendimiento de la eticidad sobre los modos de vida sociales, así como algunos esfuerzos más recientes por recuperar el ideal de bien común como horizonte crítico de las prácticas sociales transformadoras, como es el caso de François Hourtart y del propio Ignacio Ellacuría.

\section{Revisión genealógica}

Aunque los bienes comunes e igualmente, una ética del bien común de la humanidad, están excluidos del campo de lo posible, deseable y conquistable en el imaginario de la modernidad capitalista, ello no supone ninguna prueba de que no sean ni necesarios ni posibles. El capitalismo globalizado potencia los bienes privativosy particulares; privilegia a las élites poderosas frente a las mayorías populares del planeta; el bien individual o corporativo a costa del bien humano universal y del bien de la Casa común.

En este contexto, quiero hacer algunas consideraciones hermenéutico-históricas que pueden problematizar, frente a algunas interpretaciones desde la derecha y la izquierda, la pertinencia de recuperar la tradición ético-política del bien común.
Desde el pensamiento ético-político clásico griego desarrollado por autores como Platón o Aristóteles se mostró con claridad la correlación entre vida buena de los individuos y de las partes de la sociedad y el bien de la totalidad de la comunidad, personas e instituciones. Dada la interdependencia antropológica y material de los sujetos con la polis su bien hay que procurarlo y medirlo por una adecuada correlación posibilitante de unos y otros ${ }^{3}$. En este contexto, Platón señaló que "no fundamos el Estado con la mirada puesta en que una sola clase fuera excepcionalmente feliz, sino en que lo fuera al máximo toda la sociedad. Porque pensábamos que en un Estado de tal índole sería donde mejor hallaríamos la justicia, y en cambio la injusticia en el peor fundado; y tras observar uno y otro, pronunciaríamos el juicio (...) que 
buscamos. Modelamos el Estado feliz, no estableciendo que unos pocos, a los cuales segregamos, sean felices, sino que lo sea la totalidad"4. De modo semejante, indica Aristóteles que no puede ponerse en duda que el "Estado está naturalmente sobre la familia y sobre cada individuo, porque el todo es necesariamente superior a la parte. Pues una vez destruido el todo, ya no hay partes, no hay pies, no hay manos". Así, el bien del todo es superior en tanto es condición de posibilidad del bien de las partes. Igualmente reconoce que "aunque sea el mismo el bien del individuo y el de la ciudad, es evidente que es mucho más grande y más perfecto alcanzar y salvaguardar el de la ciudad; porque procurar el bien de una persona es algo deseable, pero es más hermoso y divino conseguirlo para un pueblo y para ciudades" 5 .

En esta senda, se desarrolla también la contribución de los teólogos medievales, y de los teólogos juristas renacentistas de la Escuela Ibérica de la Paz (Calafate, 2014; Calafate y Mandado Gutiérrez, 2014). Para un entendimiento reflexivo y enriquecedor de los mismos, hay superar tanto las posiciones como la de Carl Schmitt (Schmitt, 2011, cit. en Schmitt, s/f) de un lado, o más recientemente y desde otro espectro ideológico realizan Laval y Dardot. Señalan Laval y Dardot (Laval y Dardot, 2015) (después consideraremos la posición de Schmitt) que de hecho la escolástica (medieval en el caso de figuras precursoras de la escolástica como Agustín, o el caso de figura decisivas en su desarrollo como Tomás de Aquino; pero también en el caso de escolástica renacentista, como indicaría por ejemplo, la obra del jesuita Luis de Molina (15341600) actuarían en tanto que precursores intelectuales de la propiedad privada en el sistema capitalista, y en este contexto la defensa desde esta tradición de la idea del bien común como fundamento del poder, es simplemente funcional a la legitimación final de un orden públicoestatal que dé seguridad jurídica a los intercambios en el mercado capitalista. Pues bien, no niego que hayan sido tomadas algunas de sus categorías en ciertos momentos al servicio de la legitimación de la institucionalidad económica, política y jurídica de la modernidad liberalcapitalista, otra cosa, a nuestra altura histórica también pertinente, es que la función y significado histórico más adecuado a sus proyectos intelectuales no expresen sino otra racionalidad institucional alternativa, y que de hecho, las escuelas o paradigmas (Ibañez, 2018; Font, 2018 en que se sitúan expresen y ayudaran a construir otras instituciones diferentes y alternativas históricamente como en el caso de la Escuela Ibérica de la Paz, y dentro de ella la tradición espiritual y de pensamiento jesuita impulsara otras realizaciones históricas alternativas, por ejemplo, en las "repúblicas guaraníes" o también 
conocidas como "reducciones del Paraguay" 6 . Estas instituciones supusieron un freno a la modernidad capitalista en el ímpetu de mercantilizarlo todo lo disponible para la acción colonial, y de hecho, puesto que no eran funcionales a las soberanías políticas ilustradas y a los proyectos de modernización-colonización europeos, fueron eliminadas políticamente en el último tercio del siglo XVIII. Para entender más cabalmente a estos autores, hay que considerar cómo opera una interpenetración entre disciplinas (jurídicas, económicas, ...) y experiencia y saber espiritual y teológico. Si se tiene en cuenta esto, pues no eran simples juristas ni economistas, sino teólogos juristas o teólogos que se ocuparon también de la economía, esto cambia tanto el sentido conceptual de sus instituciones, como a su vez, nos da acceso a otros niveles de comprensión de la virtualidad histórica de sus categorías de pensamiento y de las realizaciones e instituciones que pusieron en marcha. En cambio, cuando sólo se toman o interpretan de modo aislado, desarraigado y no-sistemático desde el marco metodológico de la separación e incomunicación tanto de disciplinas científicas, posiciones de los diferentes sujetos, como de niveles de realidad sociohistórica, esas otras virtualidades se nos escapan.

Por ello, no puedo compartir el análisis de lo común, y del bien común en el contexto de la Tradición de la Iglesia que realizan Laval y Dardot en su libro Común (Laval y Dardot, 2015, pp.32-39). En el juicio de ellos, "[e]sta espiritualización del bien común se acompaña de una valorización de la jerarquía y sumisión al orden divino (Laval y Dardot, 2015, p. 38), dicha espiritualización se fundamenta en una "disociación entre hombre y ciudadano" (Laval y Dardot, 2015, p. 38), remitiendo al hombre en su fin a la felicidad sobrenatural o beatitud en Dios, y con ello, olvidando la ciudad terrena para ordenarlo escatológicamente a la civitas Dei. Sin embargo, a mi juicio, la crítica de Agustín al Imperio y su orden político basado en la pax romana-paz de Babilonia no busca establecer un mero ordo $u$ orden formal sino material y dinámico, no es una mera disputa por el poder de uno u otro sino por la vida justa. Para Agustín, la calidad del poder no se mide por la mera capacidad de sometimiento de todos los súbditos o de sus autoridades públicas a otro orden jurídico superior en cuanto los subsume a unos y a otros, sino por su bondad y justicia, esto es, por su capacidad de sostener en la vida y promover la vida buena de todos. Así, el orden del imperio denunciado por Agustín es injusto en su origen por la sangre derramada y la violencia deshumanizadora, y porque seguía articulándose geopolíticamente de modo inestable por la dominación entre centro y periferias colonizadas, y desde una sociabilidad humana asimétrica en una sociedad 
estamental de libres versus siervos hasta su propia descomposición, consecuencia del propio mal que practicaban ad intra y ad extra. Dios, para Agustín, no es simplemente el que está por encima del emperador y del pueblo, sino el que ama y da vida, y que tiene un proyecto salvífico vivible ya en esta vida, y por eso se puede reconocer desde la experiencia socio-histórica humana como bueno o divino, mientras que el emperador imita perversamente a Dios endiosándose y oprimiendo la vida humana ${ }^{7}$. O dicho de otra forma,y desde una perspectiva ética, la visión teológica de la realidad última en la que se desenvuelve la existencia humana es un momento segundo o derivado de lectura de la experiencia histórica humana a partir de las posibilidades de humanización que abre. Por ello, es una lectura superficial ver en la tradición cristiana medieval sólo una lucha por supremacía entre el poder del imperio, y el poder de Dios y el papado, desconociendo su fuerza profético-crítica que se funda en la espiritualidad cristiana, y con ello, la crítica de la idolatría y las posibilidades de humanización del derecho, sus instituciones yel poder ${ }^{8}$.

En este contexto, es interesante advertir desde un principio, que tras la ordenación de los bienes a lo común puede operar una "mística" que trasciende el mero ámbito de las formas de dominio humano privativo o incluso público sobre las cosas (rei) materiales o inmateriales con las que los seres humanos construyen su vida, que está presente en la espiritualidad cristiana, pero que no es exclusiva de ella. En cierto modo, los bienes tienen un carácter difusivo y comunicante que trasciende la cosificación de la mera proprietas o propiedad que quiere subsumir la cosa en su disposición para el dominus. Quizá por ello, con la influencia estoico-griega, juristas romanos de la época postclásica como Aelius Marcianus ${ }^{9}$ trataban de superar la lógica fría de apropiación privativa o colectiva a expensas de los otros humanos, es decir, la lógica de imperio o de dominio despótico (sin límites antes los otros), al menos para ciertas cosas. Así, consideraron comunes al género humano el aire, el agua que mana, el mar o el litoral, que son tratadas bajo la lógica del bien difusivo al servicio de cualesquiera sujetos humanos. En otro contexto teológico cristiano pero convergente de fondo, y a su vez también desde una influencia neoplatónica (Ramos, 2011), es atribuido al Pseudo-Dionisio el axioma bonum est diffusivum sui (Añanos, 2013), consideraba así el bien como comunicación en cuanto expresión de la donación divina, lo cual es asumido en la propia obra de santo Tomás de Aquino: "La misma naturaleza de Dios es la bondad, como es evidente en el Dionisio (Div. Nom. l) [...]. Pertenece a la esencia de la bondad comunicarse a los demás [...] (Div. Nom. IV). Por consiguiente, es propio de la esencia del bien 
supremo comunicarse de manera óptima a la criatura"10. Los bienes, que son desde la fe cristiana expresión del sumo bien, no sólo están en el tráfico jurídico para ser apropiados de un modo u otro, administrados... sino que suponen la condición posibilitante de la vida de la criatura en su ser, tener, hacer y hacerse.

Así, señala Ellacuría (Senent de Frutos, 2012, p. 278), que santo Tomás entiende a Dios como el bonum commune por antonomasia, $y$ aunque no es una idea plenamente desarrollada sí está propuesta como clave interpretativa del bien común social. En la comunidad del bien común se hace presente Dios como bien común, como Bien que se comunica y arrastra a la comunicación. Con ello, la primacía del bien común sobre el bien particular se propone así como punto de arranque frente a la privatización de los bienes.

Santo Tomás afirma, a su vez, que la bondad de una parte se considera en relación con lo que es su todo, y como el hombre es parte de la ciudad, es imposible que ningún hombre sea bueno sino por su relación al bien común ${ }^{11}$.

En esta misma línea de fondo, se puede reconocer el compromiso de la mejor tradición jesuita ${ }^{12}$ y de sus realizaciones con la centralidad del bien común (Sepúlveda, 2018) y su operativización al servicio del máximo número de sujetos, dado que según las Constituciones (Ignacio de Loyola, 1993)de la Compañía de Jesús, se indica que el bien cuanto más universal es más divino [622]. Por bien "más universal" se entiende el que "se extiende a la ayuda de más prójimos" [623]. No se trata sin más de que un supuesto bien común natural dado por Dios esté ahí para una apropiación ilimitada individual, sino de que lo divino es que el bien efectivo llegue a todos, en última instancia a la humanidad en su diversidad de gentes, y por ello, hay que ir construyendo y discerniendo las mediaciones institucionales al servicio de ese bien al que cada sujeto y comunidad está convocada a vivir y promover.

En otro contexto análogo, y frente a Carl Schmitt ${ }^{13}$, hay que decir que la racionalidad jurídica internacional 0 para el género humano en su diversidad de gentes o pueblos que desarrollan los teólogos juristas ibéricos, como Vitoria, y especialmente como Francisco Suárez ${ }^{14}$, no consiste en la legitimación de un orden internacional de Estados soberanos vaciados de moralidad y de humanidad, o reducidos a una legitimidad por legalidad, y por tanto subsumidos en una razón de Estado ${ }^{15}$. Operan criterios materiales de eticidad para la legalidad, y hay otro modo de entender el bien común desde una tensión permanente hacia convivencialidad del bien común del género humano, frente a tendencia imperial y la mera competencia asesina, pero 
reglada, del modo de hacer la guerra entre soberanos, y también frente a la mera estatalización de lo públicocomunal.

Francisco Suárez, frente a la lógica epocal de los estados soberanos en Europa que pretendían un carácter ilimitado o absoluto, defendía que esa soberanía como relativa. Por ello, es considerado unos de los fundadores del Derecho Internacional, al mostrar que existía un nivel de juridicidad entre Estados, y por tanto, también de obligaciones con respecto a los otros pueblos o Estados. Si el Estado surge y se sostiene desde el bien común, el bien común debe incluir tendencialmente a toda la humanidad, a todo el género humano. Esto se apoya, en primer lugar, en la sociabilidad natural de los pueblos o Estados. Existe una necesidad, y una capacidad de relación y de comunicación entre los pueblos. En segundo lugar, en su interdependencia. No existe un pueblo que sea en sentido estricto societas perfecta o que tenga suficiencia de bienes por sí mismo, y no necesite "relaciones exteriores" de variada índole. En tercer lugar, esto conduce a entenderla soberanía de las comunidades políticas como soberanía relativa. Es relativa porque hay un derecho común y una eticidad o racionalidad que rige las relaciones entre los pueblos en función de las obligaciones y acuerdos asumidos, y que un pueblo por sí mismo no puede derogar ese derecho común, o tratar de que esa "derogación" unilateral sea aceptada sin el consentimiento de los otros. De ahí que este bien común "internacional" sería el fundamento de la justicia entre instituciones políticas autónomas 0 independientes, en este sentido, el poder, de la índole constitucional que sea ${ }^{16}$, no lo puede todo, ni jurídica ni éticamente en sus relaciones con los otros ${ }^{17}$.

Otro aspecto relevante en Suárez es la relativa autonomía del orden político con respecto al pueblo, y por ello, no se absolutiza la instancia público-estatal. Una vez instituidas, las instituciones de la modernidad política, el Estado, la ley, no son instancias autónomas o desvinculadas sino sujetas al bien común del pueblo. Así, lo trascendente opera en lo político a través del pueblo en primera instancia y, por tanto, no hay una sacralización de lo públicoestatal o de la instancia legal. Por ello, la ley civil o humana aun cuando tiene autonomía no se mueve en una mera autofundación normativa, sino que su corrección exigirá, en su caso, que la misma sea un ejercicio de la recta razón. Por ello, la racionalidad no es absorbida o monopolizada por el poder constituido y se mantiene un punto de vista social y comunitario que puede juzgar la normatividad positivizada. 


\section{Contexto socio-político del bien común de la humanidad en la presente fase histórica}

\begin{abstract}
El bien común de la humanidad está impedido estructuralmente por la dominancia hegemónica de la forma Estado moderno-liberal en el contexto de la sociedad global. En esta forma prima, en primer lugar, la constitución vertical de un poder soberano "artificial" que es un titular diferenciado, separado y que ostenta
\end{abstract} la representación primaria del pueblo o pueblos que integran su territorio, lo que permite la primacía de la soberanía público-estatal real o potencial sobre los bienes que caen bajo el dominio jurisdiccional de su territorio estatal, y da lugar a formas propiedad pública que no son realmente co-determinadas por los sujetos colectivos que conforman la población o que surgen de la alienación de formas de propiedad anteriores. Por ello, la propiedad o bienes públicos, en este esquema y conceptualmente, compiten con las formas de bienes comunales en cuanto suponen un ejercicio de juridicidad originario de algunos sujetos colectivos. $Y$ en segundo lugar, esta forma de Estado moderno-liberal, una vez que tiene el monopolio de la producción jurídica, puede disolver las instituciones de bienes comunes que han creado históricamente sujetos colectivos a los que no reconoce en su capacidad de autodeterminación jurídica. Por ello, conceptualmente no considera ningún vínculo social con capacidad política y jurídica para gobernar y producir autónomamente reglas en la administración y uso de bienes comunes. Una vez que el vínculo social es irrelevante política y jurídicamente, y por tanto, se han atomizado los sujetos bajo jurisdicción estatal, la otra forma de propiedad que se privilegia es la propiedad privada en cuanto forma de propiedad disgregadora de los sujetos colectivos, que compiten ahora entre sí, bien como personas físicas, bien como personas jurídicas, por la maximización de su interés.

Esta lógica de la forma Estado moderno-liberal es la que ha volatizado las formas de sociabilidad y de institucionalización política de los territorios tradicionales de los diferentes pueblos, por un proceso de modernización-colonización, primero al interior del espacio político occidental, y después por su proyección sobre los otros territorios de los pueblos.

Esta forma Estado, tiene consecuencias estructurales sobre el modo de institucionalizar la satisfacción de las necesidades, así como el ámbito legítimo y "racional" de actuación sobre la naturaleza. Pues bien, en el contexto actual han entrado en crisis las formas de Estado históricamente posteriores como el Estado constitucional y el Estado social 
conquistadas en parte en el siglo $X X$ en Europa, o formas de Estado plurinacional en algunas experiencias latinoamericanas más recientes. Hoy vuelve de nuevo la forma moderno-(neo)liberal, con un énfasis nacional-populista (en Europa tanto en Estados instituidos, por ejemplo en Reunido Unido, como en reivindicaciones de instituyentes como en el caso de Cataluña o de otros territorios igualmente más ricos que otros en el ámbito del respectivo Estado) como vía única, olvidando las interdependencias a múltiples niveles, así como la responsabilidad de combatir las "externalidades sociales y ecológicas" del modelo de desarrollo liberal-capitalista, ya que la primario y transversal (a derecha e izquierda) de la agenda política de cambio es la recuperación de la soberanía e identidad nacional erosionada, o en la soberanía por conquistar en las naciones sin Estado. Junto a ello, el nacional-populismo en América Latina, además de la legitimación del despotismo en el ejercicio de la violencia por parte del aparato estatal, priman también estrategias extractivistas y el irrespeto a los pueblos originarios o la irresponsabilidad pública ante la exclusión social 0 ante los problemas medioambientales actuales. En suma, un retorno nacional-liberal que implica un marco conceptual de institucionalidad política contrario a las luchas de resistencia e instituyentes por los bienes comunes y por la reconstrucción responsable y solidaria de los sujetos colectivos o para el cambio de modelo en la relación con la naturaleza desde el ideal del bien común de la humanidad. Así, es necesario un proceso de revisión y reformulación de la forma eminente de institucionalidad política en la lucha por combatir las externalidades sociales y ecológicas que provoca el sistema moderno-capitalista mundializado. Pero enfrentar críticamente la revisión del modelo político-moderno de la forma estado/ república exige tanto en orden al bien común propio, como al bien común de la humanidad, integrar o articular la solidaridad social entre los respectivos territorios históricamente vinculados y la sostenibilidad de su sociodiversidad y biodiversidad; ampliar la solidaridad institucionalizada en las diversas regiones de la Tierra, así como unas relaciones internacionales no basadas en la competencia sino en la concertación y la cooperación.

Pero el nacional-populismo, de uno $u$ otro signo, va en direcciones contrarias a las apuntadas. Tampoco una forma Estado más avanzada que la moderno-liberal es garantía automática de bienestar, siempre subsiste, como sabemos por las experiencias históricas anteriores y actuales, la permanente posibilidad de retorno a su forma matriz primigenia modernocolonial. Y esta matriz, en el interior de los Estados, o bien sólo legitima formas de administración vertical de bienes públicos (lo que da lugar a 
expropiaciones de las comunidades de sus recursos y a la posterior puesta a disposición privada para su explotación), o a promover principalmente formas competitivas de propiedad privada y de acumulación privada sin formas institucionalizadas y efectivas de asegurar la solidaridad, responsabilizarse por la sostenibilidad social o la participación plural de actores e instituciones sociales en el desarrollo social. $Y$ a su vez, en el entorno internacional, la forma república/estado soberano estructuralmente suele primar la actuación como competidores/dominadores de los otros actores políticos estatales o pueblos de la Tierra, lo que estaría en contradicción conceptual y empíricamente, igualmente, con el bien común de la humanidad y de la Tierra.

\section{Hacia un marco categorial planetario para la justicia en la sociedad global}

A partir del contexto anterior, destaco ahora algunos aportes críticos de los últimos años que nos pueden ayudar para entender un cierto camino de transformación hacia otras formas de institucionalidad que traten de enfrentar las indigencias y las insostenibilidades sociales y ecológicas del sistema hegemónico actual. En los aportes de François Houtart y de Ignacio Ellacuría hay un común esfuerzo por articular un marco categorial de carácter planetario para orientar las luchas sociales por la justicia en la actualidad.

En este contexto, la contribución de François Houtart (Daiber y Houtart, 2012), es expresión de su cercanía y compromiso con distintos movimientos sociales en todos los continentes que le llevó a promover, junto con otros líderes intelectuales y sociales, en el seno del Foro Social Mundial un proyecto de Declaración
Universal del Bien Común de la Humanidad (Senent de Frutos, 2017). Con ello, se trataba de visibilizar y buscar la convergencia de fuerzas para desarrollar alternativas frente al modelo de desarrollo capitalista en cuanto provoca tanto la crisis ecológica global como la crisis de la mayoría de los pueblos de la Tierra que son subalternizados en este modelo de cultural y económico de desarrollo moderno-capitalista. Así, quienes son perjudicados y excluidos en este proceso de mundialización del capitalismo son, a su vez, actores de sus propias resistencias y de la construcción de alternativas al modelo hegemónico. Desde ese mapa de crisis, de víctimas, y de luchas sociales por resistir y vivir de otros modos posibles y sostenibles, se busca avanzar hacia la construcción de otra sociedad global, de otra mundialización. Pero para esa alternativa, veía preciso construir colectivamente un mapa que oriente 
y en la puedan converger las plurales transformaciones por la que luchan diversos movimientos sociales. Así, Houtart sostenía que hacía falta reconocer y sistematizar una guía de orientación sistémica para una mundialización alternativa. Los derechos humanos consensuados internacionalmente desde la segunda mitad del siglo XX no son realizables para las mayorías del planeta, y ello, justamente porque el modelo de de sarrollo capitalista globalizado, no crea las condiciones sociales para su disfrute universal. En la Declaración Universal de Derechos Humanos de 1948 se establecía como cláusula de recapitulación en su artículo 28 , que "toda persona tiene derecho a que se establezca un orden social e internacional en el que los derechos y libertades proclamados en esta Declaración se hagan plenamente efectivos". Se reconocía ya entonces que los derechos humanos no son realizables sino en el marco de un orden social y mundial que los posibilite. No se puede hacer abstracción de estas exigencias éticas y jurídicas del propio sistema vigente y efectivo de relaciones sociales donde se proyectan en cada momento de la historia estas exigencias normativas fundamentales. Por ello, necesitamos transitar hacia otro paradigma histórico que supere las contradicciones moderno-capitalistas en cuanto generador del maltrato hacia la naturaleza, de la colonización de las culturas del mundo, y de la desigualdad social en la sociedad global, y permita el disfrute de los derechos humanos y una relación justa y equilibrada con la naturaleza. Por ello, François Houtart era consciente de que caminar hacia la realización planetaria de los derechos humanos exige transformar ese sistema de relaciones o paradigma histórico globalizado generando otras estructuras sociales. Para ello, es útil y necesario generar una reflexión común que identifique las causas estructurales de la crisis social en el sistema mundial, así como que proponga los principios orientadores de nuevas estructuras sociales. Tanto ese mapa de la crisis con sus múltiples dimensiones, como el mapa de las transformaciones es lo que constituye el núcleo de la Declaración del Bien Común de la Humanidad (Senent de Frutos, 2017). Así, desde una visión sistémica e integrada se apuntan las alternativas en cada uno de los cuatro campos estructurales (ecología, economía, organización sociopolítica, cultura) para la vida social han de ser complementarias y coherentes posibilitando, a su vez, los otros campos. Con este proceso de reconocimiento de las alternativas para otra sociedad global, se busca generar un consenso, refrendado en última instancia en el ámbito de la Organización de Naciones Unidas, para reconstruir las bases civilizatorias de los pueblos de la Humanidad.

Por su parte, Ignacio Ellacuría se planteó especialmente en las décadas de los 70 y 80 del siglo 
$X X$, repensar las condiciones para una justicia cosmopolita que permitiera efectivamente realizar el bien común de la humanidad. Pero Ellacuría parte, al igual que en otros enfoques críticos, del hecho de su negación histórica para buena parte de la humanidad en la presente fase de mundialización social articulada, muy decisivamente, por un orden civilizatorio moderno-capitalista que es tendencialmente incompatible con la realización de la vida buena para los pueblos de la humanidad. Por ello, dadas las circunstancias históricas, apenas se podía hablar con verdad histórica de una única humanidad que se pudiera ver envuelta en la realización de un único bien común. Una vez cumplida la condición real de una única historia de la humanidad es ya urgente la consideración mundial de los derechos humanos; no puede olvidarse que el bien común daba paso a una estricta justicia, anterior a la voluntad de los individuos y generadora de derechos estrictamente tales, que deben ser reconocidos y promovidos por las leyes de la sociedad (Senent de Frutos, 2012, p. 278).

En esta Línea, considera Ellacuría que vistas las cosas desde el mal común real, que es "el mal que afecta a las mayorías, sobre todo cuando este mal cobra las características de injusticia estructural -estructuras injustas que apenas posibilitan una vida humana y que, al contrario, deshumanizan a la mayor parte de quienes viven sometidos a ellas - y de injusticia institucionalizada -institucionalización en las leyes, costumbres, ideologías, etc.-, surge el problema del bien común como una exigencia negadora de esa injusticia estructural e institucional. Consiguientemente el bien común, surgido como negación superadora del mal común, debe ser contrapuesto como bien al mal, pero debe tener las mismas características que hacían del mal común algo realmente común" (Senent de Frutos, 2012, p. 378). A partir de lo anterior, indica Ellacuría tres características que debe tener el bien a implantar con un carácter común o estructural que permita el sostenimiento y desarrollo humanizador de la vida humana. En primer lugar, un bien será un bien realmente común, cuando tenga la capacidad de afectar con su bondad a la mayor parte. En segundo lugar, cuando tenga de por sí esa comunicabilidad bienhechora. En tercer lugar, cuando alcance un cier to carácter estructural y dinámico, y permita por tanto una marcha de la historia humanizadora y no cosificadora o alienadora de los sujetos. Este bien común sería, por tanto, superación de una injusticia estructural e institucional, que genera una serie de estructuras e instituciones, que no sólo posibiliten, sino que contribuyan eficazmente a que "la mayor parte de los individuos -y no sólo unas minorías privilegiadas- 
puedan satisfacer sus necesidades básicas y puedan construir personal- mente sus propias vidas" (Senent de Frutos, 2012, p. 379).

\section{5. Ética del bien común concreto de la humanidad en nuestra situación histórica}

Una consideración sobre la ética del bien común de la humanidad en y para nuestra situación histórica, debe asumir la cuestión del sujeto de la ética o su presupuesto antropológico en un sentido plural, dado que los modos de humanizarse son diversos (Senent de Frutos, 2012, pp. 293-296). Por ello, a mi juicio, estamos situados en un horizonte antropológico complejo y diverso, en cuanto que lo humano puede ser modulado por diferentes tradiciones. Pero estas tradiciones y sus producciones e instituciones tienen que habérselas con la responsabilidad ética de los sujetos que participan de ellas, que no se agotan en ellas. Por eso, no deberían cerrarse, absolutizarse o totalizarse sobre sí mismas, negando la apertura relacional y responsiva en la que de facto se desenvuelven los sujetos personales o colectivos. Por ello, en un horizonte antropológico complejo y diverso, puede ser útil la consideración sistemática de los ámbitos de responsabilidad que se abren dada la estructura relacional de los sujetos, personal o colectivamente considerados. En este sentido, los sujetos pueden responder en su desarrollo o en sus actividades e instituciones, al menos, ante sí mismo/s; ante los otros con los que conviven y ante los otros que quedan fuera de sus fronteras sociales y culturales; y a su vez, tiene que responder también en sus acciones con la naturaleza que trata y los seres vivos con los que interaccionan. Por tanto, no se agotan en ser sujetos referidos a sí mismos, abstraídos del contexto real y cuyo desenvolvimiento sea ajeno a la marcha del mundo y de su propio desarrollo. En este sentido, tienen que ir co-generando y discerniendo prácticas e instituciones que le permitan una adecuada realización en el mundo junto con otros y que no impidan otras formas de realización de los otros, siempre que no causen daño o imposibilidad de actuación sostenible de otros grupos o del conjunto de la humanidad.

Pero en nuestra situación histórica real está dificultada gravemente esta capacidad relacional y responsable de los grupos humanos. El modelo de gobernanza global del sistema social mundial beneficia a algunos Estados y corporaciones, que luchan de hecho por la supervivencia y el éxito de su bloque o colectivo, aun a costa de una interacción maléfica o simplemente insolidaria con otros grupos humanos o con la naturaleza. A partir de esta estrategia que tiene una legitima- 
ción cultural, económica y política, surge un modo de practicar el propio derecho que no tiene en cuenta su corrección con respecto a los otros afectados por sus prácticas. Así por ejemplo, pueden excluir a otros grupos de sus territorios ancestrales, privar del acceso y de la capacidad de decisión sobre sus "recursos naturales", negando para ello su propia capacidad normativa, invisibilizando su modo de vivir políticamente, su propia cultura, sus saberes y técnicas y sus medios y modos de vida, por lo que pueden pasar a ser poblaciones irrelevantes, sin futuro, abocadas a la extinción o a la muerte rápida o lenta, excluidas o explotadas en un intercambio desigual y neocolonial.

En esta línea, podemos tratar de reconocer criterios para la selección, crítica y transformación de los sistemas en pugna en el horizonte de una ética del bien común de la humanidad. Tanto los sistemas normativos verticalizados y heterodeterminados (Estatales en el contexto modernoliberal), que legitiman tanto formas de propiedad pública (competitivas a nivel internacional) y no sujetas a control social, como formas de propiedad privada que de facto benefician a los más fuertes en la competencia social; como los sistemas normativos horizontales y autodeterminados precisan de criterios de discernimiento y de orientación para el mantenimiento, adopción, construcción o transformación de esta pluralidad normativa.
Desde el contexto anterior, señalamos que una ética del bien común concreto de la humanidad se puede expresar en la articulación ideal pero historizable y dinámica de tres dimensiones interdependientes de cada práctica o sistema institucional: ser verdadero, justo y ajustado/ factible. Son dimensiones porque son momentos de una unidad sistemática. En este sentido, las dimensiones nos sirven para reconocer criterios del bien común. En cuanto "concreto", puede ser practicable o universalizable en cuanto dependa del acierto de la acción social humana o de la institución que se despliega. En cuanto "dinámico" tiene que ir buscando viabilidad y reajustándose en vista de una corrección integradora de las prácticas e instituciones. Pero si un criterio no se satisface en un grado adecuado, se imposibilita la realización de la actividad humana para integrar el bien de la humanidad experimentable, compartible y no imposibilitante. Así, su realización en un mayor o menor grado, se sitúa idealmente entre polaridades que son la verdad o falsedad, justicia o injusticia y ajuste o desajuste ${ }^{18}$ (factibilidad o no factibilidad) de las prácticas humanas. Estas polaridades, pues, se mueven y experimentan entre el bien común y el mal común. Esto es, entre la afirmación o sostenimiento tendencialmente viable $\mathrm{y}$ reproducible de una verdadera vida buena, justa y viable, y a su vez, no imposibilitante por acción u omisión de una vida buena sostenible de los 
otros, o en última instancia de todos los sujetos y los pueblos de la Tierra; o en el fracaso o colapso de la actividad humana del propio grupo, o en la negación o impedimento de una vida buena sostenible de los otros, o en última instancia, de los sujetos y pueblos de la Tierra.

Estas dimensiones en su conjunto sostienen, orientan y juzgan la calidad de las prácticas institucionales que los diferentes grupos de la humanidad desarrollan o tratan de desarrollar en función de su refluencia benéfica sobre el bien común de la humanidad, y ello por constituir hoy la sociedad global una sociedad "única" (aunque sea asimétrica en la distribución de poder de los diversos grupos o bloques, y aunque sea diversa socioculturalmente), dada la interdependencia que de facto configura las posibilidades de realización y de suficiencia de bienes de cada grupo social.

Así, si tratamos de hacer una consideración analítica ${ }^{19}$ de las prácticas sociales e instituciones en el contexto del bien común global o de la humanidad podríamos considerar:

\subsection{Criterio de verdad desde el bien común de la humanidad}

En un primer sentido, haría referencia al momento de verdad formal o de verdad pretendida socialmente. La pregunta crítica para su contraste puede ser si las prácticas e instituciones están verdaderamente universalizadas, esto es, si incluyen a todos los miembros de su grupo en su disponibilidad, o son instituciones "ideologizadas" en cuanto no realizan lo que prometen y de facto sirven la legitimar y ocultar prácticas sociales que niegan el alcance real los ideales que amparan lo proclamado. ${ }^{20}$

En un segundo sentido, haría referencia al momento de verdad antropológica y cultural. La pregunta crítica para su contraste puede ser si la práctica o la institución articula un modo de sostenimiento y realización auténticamente humanizadora para sus actores, o bien si es deshumanizante por su capacidad de afectar maléficamente a los otros; o es inhumana por la ruptura que implica con la vida de los otros.

Y en un tercer sentido, haría referencia al momento de verdad en sentido intercultural. La pregunta crítica para su contraste puede ser si las plurales prácticas normativas y sus respectivas instituciones $y$ subsistemas contribuyen a la sostenibilidad sistémica global, o no impiden otros modos de vida sostenibles y de practicar el Derecho a otros grupos humanos y sociales, 
y si son por tanto respetuosos con los procesos de autodeterminación colectiva de la plural constitución de la humanidad. Ello implica la necesidad de no impedir la pluralidad normativa de las sociedades, pero a su vez que este carácter de pluralidad, se articule y oriente normativamente en función de la convivialidad que genera, tanto con respecto a otros pueblos como en cuanto a la universalidad convivencial que alcanza entre sus miembros. Así, un subsistema jurídico puede ser interculturalmente denunciado o enjuiciado por el carácter excluyente 0 imposibilitante de otros modos de vida, o por la desigualdad de sus propios miembros relegados o excluidos, teniendo en cuenta que esos otros modos de vida, tienen para pretender legitimidad, verdad o validez intercultural, que ser universalizables materialmente y por tanto, tendencialmente compatibles con el respeto del ejercicio y la continuidad la vida humana y no humana en la Tierra.

\subsection{Criterio de justicia. Momento de justicia social-global y ecológica}

El criterio de corrección formal o de justicia de las prácticas e instituciones sociales que configuran o integran el bien o mal común, dada la interacción social planetaria ya no puede definirse por referencias puramente internas con respecto a un grupo humano políticamente constituido como en la tradición del pensamiento clásico. Por ello, es preciso articular un criterio de justicia entendida como bien común humano universal, donde también se dé y articule un cierto bien común de la naturaleza en el que se desenvuelven las prácticas de la propia humanidad. $Y$ ello porque el proceso de unificación fáctica y su consiguiente crecimiento en interdependencia entre las condiciones de vida humana y no humana, genera la convergencia del bien o mal humano con el bien o mal ecológico.
Así, en cuanto al momento de justicia social-global, las plurales prácticas sociales pueden ser evaluadas como correctas o justas, o incorrectas o injustas a la luz de su capacidad de configuración o de negación de ese bien común global. De lo que la experiencia social parte con más frecuencia es de su ausencia o negación, es decir, de la experiencia del mal común, que es lo que se da de hecho para muchos grupos humanos que no pueden sostener una existencia social satisfactoria en tanto están mal afectados por estructuraciones sociales que impiden su propio y correcto desenvolvimiento personal y grupal, como ocurre a partir del modelo de gobernanza liberal del sistema mundial, que se impone verticalmente impidiendo de hecho la realización o el disfrute de sus propios sistemas jurídicos para muchas sociedades. 
En cuanto al momento de justicia ecológica, está también imbricada con la justicia social pues hoy esa experiencia del mal común humano, se ve agravada por la negatividad para las condiciones sociales de vida, e incluso sobre sus propias vidas humanas en un sentido biológico, tiene el mal común ecológico. El proceso de destrucción de la naturaleza en la presente fase histórica, donde el propio modelo de desarrollo socioeconómico moderno tiene buena parte de responsabilidad, está socavando las propias condiciones de vida humana, y aún las propias vidas humanas. Ello es lo que exige que el ideal utópico o el criterio normativo de corrección sea la superación de esa negatividad vivida. De este modo, el proceso de abuso de los recursos naturales y de alteración de los ciclos naturales que está generando la actividad humana, produce ya una visible injusticia social para ciertos grupos, que no se benefician de ese proceso destructivo, sino que sufren sus consecuencias más directamente, y a su vez, está poniendo en riesgo de colapso la continuidad del conjunto de la actividad humana en el planeta. Esta negatividad sentida, y conocida cada vez mejor, demanda la reorientación del criterio hacia un criterio utópico de justicia social incluyente globalmente y también descentrado, que incluya la justicia ecológica o ambiental. Si queremos seguir viviendo y no solo empobreciendo nuestra especie, sino acrecentando nuestra humanidad, tenemos que orientarnos por un bien común humano universal y sociodiverso donde también se integre el bien de la naturaleza en la que se desenvuelven las existencias humanas. Por ello, hoy las prácticas sociales orientadas normativamente si quieren ampliar y plenificar la existencia humana, no están desconectados de otras exigencias de la realidad, dadas las otras alteridades en las que se desenvuelve la praxis humana, incluida la propia corporalidad. Estas exigencias, se pueden formular humanamente como deberes ante la naturaleza (Senent de Frutos, 2009), o incluso como derechos de la misma, toda vez que la propia praxis humana puede reconocer otras fuentes de deberes o derechos que no sean sólo interhumanos.

\subsection{Criterio de ajuste, sostenibilidad o factibilidad. Momento social y ecológico.}

La búsqueda de la corrección normativa de las prácticas e instituciones sociales precisa, a su vez, reconocer un criterio de ajuste, justeza o de corrección material para esas prácticas que se orienta por la búsqueda de la factibilidad social juzgada por su capacidad de reproducción social de la respectiva práctica o institución, y en última instancia, por su afectación de la capacidad de la humanidad de 
actuar en el presente y en el futuro. Pero la factibilidad social tiene que hacerse viable ecológicamente o no impedir la factibilidad ecológica o la sostenibilidad natural de la vida humana en el conjunto de la naturaleza, así como la continuación de la biodiversidad.

Así, el ideal de justeza, cualifica el criterio utópico de justicia de un mundo donde tendencialmente quepan todos, presentes y futuros, y tengan vida digna viable o sostenible. La justeza implica un cierto "acoplamiento", de unos seres y actividades con los otros y entre los otros. "Caber" es estar entre los otros sin que se impida con ello las otras vidas. Y no sólo por el asesinato directo, de ahí la importancia del no matarás en cualquier sistema social, pero también del "asesinato indirecto" como modo de exclusión desde las prácticas sociales, económicas, políticas, culturales que impiden o dificultan las prácticas de otros en su dimensión social, de satisfacción de las necesidades materiales, de participación política, de construcción y expansión cultural. Y así también, esa cabida hoy se reconoce desde la dimensión ecológica de intercambio con los otros seres vivos en el conjunto de la naturaleza. Ello implica la renuncia a un mundo donde tendencialmente sólo la especie humana, o más bien una minoría de ella y un único modelo realización cultural, pueda desplegar libremente su actividad, mediante el empobrecimiento y exclusión creciente de la biodiversidad natural y de la sociodiversidad humana.

\section{Hacia un diálogo entre la ética y espiritualidad para el bien común de la humanidad}

Tras una ética del bien común de la humanidad, hay un discernimiento de los fines de la vida humana, es decir, del modo de racionalidad que se está articulando en este proceso histórico. Por ello, no hay sólo "soluciones técnicas" como si una razón técnica o un simple pensar calculador resolviera el tipo de instituciones a desarrollar en función de los requerimientos de las sociedades particulares o de la propia humanidad. No hacen falta sólo instituciones que resuelvan, y para ello se institucionalicen/regulen jurídicamente y se sostengan políticamente a diferentes escalas, sino que estas se integran en un contexto mayor que podríamos llamar una racionalidad de fines en el marco de la acción humana. Es por ello que necesitamos articular soluciones técnico-sociales con un saber acerca de los fines. Pero una racionalidad de fines que no sea puramente abstracta sino propia de un horizonte humano, debe también de considerar qué tipo de ser humano configura una u otra solución, y con ello, discernir también entre las vías de humanización. 
Ellacuría ya mostró cómo tras el tipo de actividad o de modulación de unas prácticas sociales pende también, inexorablemente, un tipo de camino de humanización (Ellacuría 2001b) o de deshumanización. Este camino debe ser reconocido y discernido según su calidad antropológica. Por ello, no se trata sólo en el mejor de los casos de alcanzar un modo de vida que sea universalizable, sino que tras la realización pende un modo de realizar-se. Es decir, hay un modelo humano concreto configurado de un modo u otro según los valores dominantes incorporados a las actividades sociales en cuyo carácter sistemático e interdependiente expresa una concreta dinámica civilizatoria.

Pero estas vías de humanización radicalmente consideradas constituyen un problema espiritual y político (no de meras creencias ideológicas o religiosas). Por ello entiendo que es el cuidado de la interioridad una condición socio-política imprescindible para configurar eficazmente las relaciones sociales, tanto a nivel interno como en sus interacciones (locales, territoriales, estatales, regionales o globales) así como la responsabilidad humana en la transformación de las estructuras opresoras del mundo. Un abandono a-crítico de lo que se proyecta interiormente en la configuración de mundo es una vía adecuada para mantener la marcha histórica encaminándose hacia el fracaso colectivo. Es preciso una atención a las diversas "posiciones espirituales", que no es una cuestión evanescente sino concreta y que se materializa y objetiva en las vidas posibilitadas o negadas. En este sentido, es crítico para un compromiso político-transformador un cuidado ético y espiritual de la interioridad de las subjetividades personales, colectivas, o públicopolíticas que en su modo de situarse y proyectarse en la producción de mundo están determinando la apertura o el cierre de las posibilidades de vida humana y no humana en el conjunto de la sociedad global. Es en sus interacciones ante las otras instancias reales, objetivables por los niveles de bien o mal común (de reproducibilidad de la vida compartible, o de cierre y agotamiento de la vida presente y futura) donde se verifican históricamente las diversas "posiciones espirituales". Pero es en el cuidado reflexivo y sapiencial de los procesos interiores de las diversas subjetividades apuntadas, donde se pueden liberar formas nuevas 0 recuperadas de mediaciones institucionales más humanizadoras que se muevan en el horizonte del bien común de la humanidad. 


\section{Referencias bibliográficas}

- Añanos Meza, M. C. (2013). La doctrina de los bienes comunes en Francisco de Vitoria. Persona y Derecho, Vol. 68, n 1, p. 107, nota 7.

- Calafate, P. (2014). A Escola Ibérica da Paz nas universidades de Coimbra e Évora (séculos XVI e XVII). Revista de hispanismo filosófico. $N^{\circ} 19$, pp. 119-142

- Calafate, P. y Mandado Gutiérrez, R. E. (Eds.) (2014). Escuela lbérica de la Paz: La conciencia crítica de la conquista y la colonización de América. Santander: Universidad de Cantabria.

- Daiber, B. y Houtart, F. (2012). Un paradigma postcapitalista: el bien común de la humanidad. Panamá: Ruth Casa Editorial.

- Ellacuría, Ignacio. (2001a). Escritos filosóficos (II). San Salvador: UCA Editores.

- -------- (1996). Escritos políticos (I). San Salvador: UCA Editores. - (2001b). Escritos teológicos (IV). San Salvador, UCA Editores.

- Font Oporto, P. (2018). La facticidad de la filosofía política de Francisco Suárez: un camino hacia otra Modernidad. Pensamiento, Vol. 74, n² 279,pp. 179-200.

- Ibáñez Ruiz del Portal, E. (2018). Francisco Suárez y los derechos humanos. Corrientes historiográficas y perspectivas críticas actuales. Pensamiento, Vol. 74, n² 279, pp. 221-235.

- Ignacio de Loyola. (1993). Constituciones de la Compañía de Jesús. BilbaoSantander: Mensajero-Sal Terrae.

- Laval, C. y Dardot P. (2015). Común. Ensayo sobre la revolución en el siglo. Barcelona: Gedisa.

- Melià, S. J., B. (2018). Las reducciones jesuíticas de guaraníes en el marco teológico jurídico de la Escuela Ibérica de la Paz. Antíteses. Vol. 21, pp. 18-38.

- Papa Francisco. (2015). Laudato si. Sobre el cuidado de la casa común. Madrid: San Pablo.

- Pereña Vicente, L. (1956). “Estudio preliminar" en Pereña Vicente, L. (Ed., trad. y notas) Francisco Suárez, Guerra, Intervención y paz internacional. Madrid: Espasa-Calpe, 1956. 
- Periñán, B. (2018). El mar, ¿res communis omnium? Dogma y realidad desde la óptica jurisprudencial. RIDROM. Revista Internacional de Derecho Romano. $N^{\circ} 21$, pp. 688-691.

- Ramos, Alice. (2011). La causalidad del bien en santo Tomás. Anuario filosófico. Vol. 44, n 1, pp.112-113.

- Schmitt, Carl. (2011) Der Nomos der Erde im Volkerrecht des Jus Publicum Europaeum. Berlín: Duncker \& Humblot.

- ------- (s.f.) El nomos de la Tierra en el Derecho de Gentes del Jus publicum europaeum. Buenos Aires: Editorial Struhart y Compañía.

- Senent de Frutos, A. (2016). Der Kampf um das Recht. Geschichte und Transzendenz. En Sebastian Pittl y Gunter Prüller-Jagenteufel (Eds.) Unterwegs zu einer neuen "Zivilisation geteilter Genügsamkeit". Perspektiven utopischen Denkens 25 Jahre nach dem Tod Ignacio Ellacurias. Viena:Vienna University Press, pp.145-158.

- Senent de Frutos, A. (2009). Ecología y problemas medioambientales. Orientaciones para la praxis desde otro marco cultural. Revista de Fomento Social. No 256, pp. 699-708.

- Senent de Frutos, A. (2017) François Houtart y la Declaración Universal del Bien Común de la Humanidad. Revista de Fomento Social. Vol. 72, $\mathrm{n}^{\circ}$ 2, pp. 307-318.

- Senent de Frutos, A. (2013). "Hacia un derecho sostenible o factible para la humanidad”. En Carlos Alonso Bedate S. J. (Ed.). ¿Es sostenible el mundo que vivimos? Un enfoque interdisciplinar. Madrid: Editorial Universidad Pontificia de Comillas, pp. 259 - 291.

- Senent de Frutos, A. (2014). Hacia una relectura de la matriz cultural ignaciana desde nuestras necesidades civilizatorias actuales. Concordia. Revista internacional de filosofía. $N^{\circ} 66$, pp. 25-48.

- Senent de Frutos, A. (2016). Ignatian Modernity as another kind of Modernity. En Hans Shelkschorn y Herman Westerink (Eds.). Reformation(en) und Moderne. Philosophisch-theologische Enkungurden. Viena: Vienna University Press, pp. 153-171.

- Senent de Frutos, A. (Ed.) (2012). La lucha por la justicia. Selección de textos de Ignacio Ellacuría (1969-1989). Bilbao: Universidad de Deusto.

- Sepúlveda del Río, I. (2018). El bien común en los inicios de la Compañía de Jesús: desde los primeros años hasta el pensamiento de Francisco Suárez. Pensamiento. Vol. 74, nº 279, pp. 163-178. 


\section{Notas}

1 Algunos aspectos de este artículo fueron presentados y discutidos anteriormente en la ponencia presentada en el Simposio "Justicia y responsabilidad en la sociedad global", celebrado del 28 al 30 de abril de 2019 en la Universidad Católica de Eichstätt-Ingolstadt.

2 "Heidegger pensaba (Was ist Metaphysik?) que era la nada la que fundamentaba la posibilidad del no y,en general, de la negatividad; por ello, quizá, en vez de preguntarse por qué hay más bien ente que nada, debería haberse preguntado por qué hay nada -no ser, no realidad, no verdad, etc.- en vez de ente" (Ellacuría, 1996, p. 101).

3 En este sentido, Ignacio Ellacuría reconoce la dos razones que fundamentan la idea de bien común en que "la sociedad es una realidad necesaria para el individuo (la sociedad, en el sentido de polis, civitas, esto es, sociedad política) y la sociedad no puede ser lo que es, ni hacer lo que debe hacer si no cuenta con suficientes recursos materiales, que estén a disposición de todos y cada uno de los individuos" (Senent de Frutos, 2012, p. 275.

4 República, $420 \mathrm{c}$.

5 Ética a Nicómaco, 1094b.

6 En esta línea, destaco la contribución de Bartomeu Melià, SJ, "Las reducciones jesuíticas de guaraníes en el marco teológico jurídico de la Escuela Ibérica de la Paz" (Melià, 2018). En este trabajo, Melià muestra cómo la tradición jesuita que se proyecta en la "Escuela Ibérica de la Paz", especialmente a través de autores como Suárez, puede verse en sintonía con las realizaciones de las reducciones guaranies.

7 Cf. Agustín de Hipona, Civitate Dei, lib. XIX, cap. 7 y 9.

8 Sobre la capacidad de trascendencia histórica en términos de Ignacio Ellacuría, o capacidad profético-crítica de la tradición y espiritualidad cristiana en la lucha por el derecho y sobre el problema de la secularización moderna y hegemónica del Derecho, la distinción de esferas y su servicio a los más fuertes he escrito en Senent de Frutos: 2016.

9 Dig. 1,8,2,1 (Marcian. 3 inst.) "Et quidem naturali iure omnium communia sunt illa: aer, aqua profluens, et mare, et per hoc litora maris". Cit. en Perilán, 2018.

10 Tomás de Aquino, Summa Theologiae III, q. 1, a.1, resp.: “Ipsa autem natura Dei est bonitas, ut patet per Dionysium, I cap. de Div. Nom. Unde quidquid pertinet ad rationem boni, conveniens est Deo. Pertinet autem ad rationem boni ut se aliis communicet, ut patet per Dionysium, IV cap. de Div. Nom. Unde ad rationem summi boni pertinet quod summo modo se creaturae communicet."

11 Tomás de Aquino, Suma Teológica 1-2, q. 92, a. 1, ad 3.

12 Decimos "mejor" en un sentido evaluativo desde nuestra altura histórica, y por contraste con otros desarrollos o apropiaciones de otros autores y corrientes fundamentalmente funcionales a la modernidad capitalista. (Senent de Frutos, 2014; Senent de Frutos, 2016).

13 "El Derecho de Gentes europeo, postmedieval, de la época interestatal de los siglos XVI a XX trata de relegar la causa justa. El punto formal de apoyo para la determinación de la guerra justa ya no es la autoridad de la Iglesia basada en el Derecho de Gentes, sino la soberanía de los Estados en igualdad de derechos. La ordenación del Derecho de Gentes interestatal parte ahora del iustus hostis y no de la iusta causa y considera toda guerra interestatal, entre dos soberanos en igualdad de derechos como guerra justa. Mediante esta formalización jurídica se logró una racionalización y humanización o, en otras palabras, una acotación de la guerra (...) A fin de restablecer la auténtica imagen de Vitoria [y Suárez también como precursor] 
es suficiente, pero también necesario, tener en cuenta que en la historia del Derecho de Gentes, la transición de la Edad Media a la época moderna se caracteriza por una separación doble entre dos órdenes de pensamientos que en el Medievo eran indivisibles: la separación definitiva entre la argumentación teológico-moral y eclesiástica y la argumentación jurídicoestatal, y la separación, igualmente importante, entre la cuestión jurídico-natural y moral de la iusta causa y la cuestión típicamente jurídico formal del iustus hostis, que es distinguido del criminal, o sea del autor de una acción punible. Estos dos puntos representan el paso decisivo del Derecho de Gentes medieval a un Derecho de Gentes de la época moderna, de un sistema de pensamiento teológico-eclesiástico a un sistema de pensamiento jurídicoestatal" (Schmitt, 2011).

14 De Legibus (Madrid: CSIC, 1975), Libro III, c 3, n 8, 35.

15 Estoy más conforme con Luciano Pereña para quien "El Estado [salvo que se absolutice en sus relaciones con otros pueblos] no ha destruido la humanidad, ha hecho posible su evolución. Francisco Suárez ha descubierto esta primera relación entre los Estados que se manifiesta es la amistad y la caridad entre todos los hombres. Por el principio de sociabilidad, los pueblos se unen y se ayudan, cooperan en un bien más general que sacrifica la razón de Estado"(Pereña, 1956).

16 Por poner un ejemplo, ni siquiera en el caso de los príncipes cristianos, por su condición de tales, es signo para Suárez de una superioridad político y moral sobre los príncipes paganos: "El poder, tal como se da hoy en los gobernantes cristianos, no es mayor ni de distinta naturaleza que lo fue en los gobernantes paganos. Luego de suyo, no tiene otro fin ni otro objeto", De legibus..., libro III, c XI, n 9.

17 Como señala Luciano Pereña, "contra el imperialismo y el cesaropapismo, [Suárez] defendió la igualdad jurídica de todos los pueblos independientemente de su religión, de su raza y de su cultura. [...] Sobre este principio de igualdad y libertad era posible la unión entre pueblos y la paz internacional" (Pereña, 1956, p. 39).

18 Utilizo de una forma ampliada esta tríada analítica articulada por Ignacio Ellacuria por su capacidad de intelección crítica, compleja y sistemática de la actuación humana (Senent de Frutos, 2012, pp. 365-375).

19 Un análisis de la integración de la sostenibilidad jurídica de las prácticas e instituciones en el conjunto de los subsistemas que posibilitan estructuralmente la acción social la he realizado en "Hacia un derecho sostenible o factible para la humanidad", en ¿Es sostenible el mundo que vivimos? Un enfoque interdisciplinar (Senent de Frutos, 2013).

200 de otro modo, lo que plantea Ellacuría en la pregunta por el grado de verdad (real o histórica) del bien común idealmente afirmado socialmente o legitimado: "verifica[r] cuán común es el bien propuesto como bien común, esto es, a cuántos y de qué modo alcanza la utilización de ese bien común".(Senent de Frutos, 2012, p. 282). 